\title{
Electron beam welding of rectangular copper wires applied in electrical drives
}

\author{
Tamás Tóth $^{1}$ · Jonas Hensel ${ }^{1}$. Sven Thiemer ${ }^{2} \cdot$ Philipp Sieber $^{3} \cdot$ Klaus Dilger $^{1}$
}

Received: 31 January 2021 / Accepted: 2 July 2021 / Published online: 9 August 2021

(c) The Author(s) 2021

\begin{abstract}
The so-called hairpin winding technology, which is specially tailored to electrical traction components, deploys rectangular plug-in copper wires in the stator. The fusion welding of the adjacent wire ends is associated with challenges due to the high thermal conductivity as well as the porosity formation of the copper. During this study, the electron beam (EB) welding of electrolytic tough pitch (ETP) and oxygen-free electronic grade (OFE) copper connectors was investigated. Subsequently, the specimens underwent X-ray computed tomography (CT) and metallographic examinations to characterize the joints. It was discovered that the residual oxygen content of the base material is responsible for the pore formation. With only a very low level of oxygen content in the copper, a porosity- and spatter-free welding can be reproducibly realized using the robust EB welding technology, especially for copper materials. By optimizing the parameters accordingly, joints exhibiting a low level of porosity were achieved even in the case of the alloy containing a high amount of residual oxygen. Beyond this, detailed analyses in terms of pore distribution were carried out and a good correlation between technological parameters and welding results was determined.
\end{abstract}

Keywords Copper $\cdot$ Electron beam welding $\cdot$ E-mobility $\cdot$ Residual oxygen $\cdot$ Porosity $\cdot$ X-ray computed tomography

\section{Nomenclature}

EB Electron beam

$\mathrm{Cu}$-ETP Electrolytic refined, oxygen-containing copper

Recommended for publication by Commission IV - Power Beam Processes

Tamás Tóth

t.toth@tu-braunschweig.de

Jonas Hensel

j.hensel@tu-braunschweig.de

Sven Thiemer

sven.thiemer@pro-beam.com

Philipp Sieber

philipp.sieber@pro-beam.com

Klaus Dilger

k.dilger@tu-braunschweig.de

1 Institute of Joining and Welding, Technische Universität Braunschweig, Langer Kamp 8, 38106 Braunschweig, Germany

2 pro-beam Systems GmbH, Auer Straße 19a, 09366 Stollberg/Erzgebirge, Germany

3 pro-beam $\mathrm{GmbH} \&$ Co. KGaA, Zeppelinstr. 26, 82205 Gilching, Germany

$\begin{array}{ll}\text { Cu-OFE } & \begin{array}{l}\text { High purity, oxygen-free, non-phosphorus- } \\ \text { deoxidized electronic grade copper }\end{array} \\ \text { MIG } & \text { Metal inert gas } \\ \text { DoE } & \text { Design of Experiments } \\ \text { CT } & \text { X-ray computed tomography } \\ A & \text { Cross-section of the rectangular wires } \\ M & \text { Mean cross-sectional area of the joints } \\ \sigma & \text { Standard deviation of the joint cross-section } \\ \psi & \text { Sphericity } \\ V_{\text {pore }} & \text { Volume of a pore } \\ A_{\text {pore }} & \text { Surface of a pore } \\ F & \text { Oscillation frequency } \\ w & \text { Oscillation width } \\ f & \text { Defocusing }\end{array}$

\section{Introduction}

\subsection{Fundamentals of the hairpin technology}

In recent years, the share of hybrid and electric cars increased rapidly due to the stricter environmental regulations and advancements of electronics. All of such concepts include a semi-electrified powertrain or a fully electrified 
powertrain and thus require new approaches in the design as well as in the manufacturing. Due to the massive shift from the combustion engines towards the electric alternatives, new solutions have been developed. Here, the components of an electric motor should comply with the demand of excellent drivability, energy management, and at the same time reliable, efficient, and traceable mass production. One prospering approach is the so-called hairpin winding technology of the stator, the key element of an electric motor, where pluggable rectangular copper wires are used. This method increases the energy density, enabling higher power output and consequently better efficiency with a more compact implementation. Although, alongside the benefits, the hairpin winding brings challenges for the assembly, as well as for the joining technologies [1]. One typical manufacturing sequence is the welding of adjacent wire ends, so that the electrical circuit is closed. Depending on the requirements and the present construction, this process step can be performed either with pressure or with fusion welding processes.

\subsection{Laser and electron beam welding of copper}

The common fusion joining processes are associated with fundamental challenges attributed to the physical properties of the copper. Firstly, the high thermal conductivity results in the rapid cooling of the weld zone [2,3], requiring sufficient energy density or even preheating for the welding process. When using unsuitable technology, this property may lead to an incomplete fusion or lack of penetration. Secondly, the high thermal expansion increases the distortion of the part. Processes with high energy density and resulting narrow welding zone, such as power beam technologies, are therefore gaining increasingly in significance, complying also with the demand for a quick and automated welding. Here, the most established technology is the laser beam welding, followed by the electron beam process. Although, the laser beam welding is facing further difficulties when welding copper due to its high reflectivity at wavelengths characteristic for the common beam sources [4, 5]. Especially at higher wavelengths (such as $10600 \mathrm{~nm}$ ) in the infrared regime, which is emitted by the common $\mathrm{CO}_{2}$ laser sources, severe difficulties arise [5]. Since only a tiny fraction of incident laser light is absorbed, very high power should be applied to realize a fusion process. Hence, novel solid-state laser sources are frequently used to enhance the welding possibilities by improving the coupling to the base material. Among the commonly applied solid-state lasers, the Nd:YAG sources show better coupling to reflective materials, especially in the molten phase [6]. The recent developments of laser beam sources and the resulting higher output powers, better beam qualities, and the reduced spot sizes have opened the possibility of keyhole welding mode, which leads to higher penetration depths and better productivity [7]. Once the keyhole is stable, a further increase in process efficiency takes place, as the majority of the light is being entrapped in the cavity. Exploiting these possibilities, many researchers focused on the laser beam welding of copper alloys. Zhang et al. [8] reported about the laser beam welding of copper sheets at high welding speed. The authors discovered that the spatter formation and the undercut defects gradually decrease as the welding speed increases. The amount of spatter and the resulting material loss can be effectively reduced by welding slightly below the critical welding speed for a full penetration at a given power. In terms of electrical properties, the base metal and the welded joint exhibit a similar conductivity. It was furthermore discovered that the tensile strength, as well as the elongation, significantly decreased compared to the base metal. Additionally, a comparative study on the microstructure and properties of copper joints between metal inert gas (MIG) welding and laser-MIG hybrid welding was conducted [9]. As the incident laser beam couples into a material, which is already in molten phase due to the energy of the MIG source, the coupling efficiency greatly increases. The authors discovered that joints produced by the hybrid process exhibited a higher tensile strength and a narrower heat-affected zone, but also a higher susceptibility to defects such as undercut or pores than that welded solely by MIG. Further improvement possibility is the utilization of lower wavelengths located in the range of the green and blue light, additionally improving the absorption of the incident beam [10,11]. However, due to the state-of-the-art, only relatively low powers can be utilized, impeding the possibilities of a deep penetration welding. Another problematic issue is the porosity formation due to the presence of residual oxygen when welding such alloys. Normally, the residual oxygen content is present in the form of various oxides along the grain boundaries, which are dissociating during remelting. In molten state, the copper solves more than 150 at. ppm oxygen [12]. In contrast to that, at room temperature, it drops below 5 at. ppm. Therefore, the consequent porosity formation is mostly attributed to the limited oxygen solubility of the copper, causing gas pore formation during solidification. Furthermore, the presence of oxygen also entails the risk of hydrogen embrittlement, especially when using reducing atmospheres or having contaminated surfaces [13]. To overcome these barriers, the electron beam welding can be taken into consideration, as a predestinated process for joining of copper alloys. Using this technology, high-quality welding can be achieved due to its excellent beam quality, high power, and great flexibility [14]. Furthermore, since the energy is delivered through electrons, highly reflective materials can be welded without difficulties observed in the laser beam technologies. The electron beam welding is normally carried out in high-vacuum, which guarantees a clean welding, preventing the surface from 
oxidation or undesired chemical reactions. The presence of vacuum also enhances the degassing of the melt pool, reducing the residual porosity in the weldment. Due to these benefits, the electron beam welding of copper alloys remains in focus for researchers. Johnson [15] has carried out electron beam welding tests on phosphorus-deoxidized copper with high (Cu-DHP) and low (Cu-DLP) residual phosphorus content, as well as on oxygen-free high conductivity $(\mathrm{Cu}-$ OFHC) alloy. It was observed that the porosity greatly increases with the decrease of the travel speed and the rise of the beam power. It has been also reported that moving the focal point below the surface increases the penetration and the porosity. Based on the results obtained at the applied materials, the impurities do not effect on the porosity according to the author. In addition, the beam size and the energy density have a crucial effect on the result; hence, accurate monitoring is recommended. Kanigalpula et al. [16] conducted a study on the optimization of penetration for electron beam welding of electrolytic tough pitch copper $(\mathrm{Cu}-$ ETP) plates. They reported that the deepest penetration was achieved at high accelerating voltage, high beam current, medium frequencies $(600 \mathrm{~Hz})$, and low amplitudes of the oscillation. The standard deviation of the penetration can be reduced, and consequently, the spiking phenomenon can be suppressed when using low accelerating voltages, moderate beam currents, high frequencies, and high amplitudes of oscillation, applying also a slight under-focusing (focal point below the surface). Kar et al. [17] realized copper-stainless steel dissimilar weldments, using both oscillating and nonoscillating beams. The joints were subsequently characterized by using CT scanning. It was discovered that generally, the beam oscillation decreased the amount of porosity and also reduced the individual pore sizes. Although, beam oscillation beyond an optimum diameter led to the reincrease of the porosity formation. The authors also reported a strong correlation between the individual pore sizes and the sphericity values (the calculation method is explained in Section 2.4). The small pores up to $60 \mu \mathrm{m}$ in diameter mostly had sphericity values between 0.6 and 0.9 . However, when the pores were larger, the sphericity values decreased to $0.4-0.7$. The main reason for this phenomenon is that the larger pores tend towards being irregular or having an amorphous shape. This leads to a decreased sphericity. Based on the previous results, the flexibility of the electron beam welding could be beneficial in welding of copper connectors. Dynamic beam oscillation can be used to improve the degassing conditions, to a great extent. By defocusing, the modification of the energy distribution as well as the enlargement of the weld pool surface takes place. Furthermore, the presence of vacuum is also beneficial for the degassing and the reduction of spatter formation. A hydrogen-free, clean work environment eliminates the risk of hydrogen embrittlement when welding copper alloys containing oxygen. The overarching goal of the underlying study is to gain a better understanding of the porosity formation in different grades of copper. This knowledge is essential for the reliability and further development of the welding process.

\subsection{X-ray computed tomography of weldments}

X-ray computed tomography (CT) has been strongly exploited in the material science in recent years, exhibiting benefits in testing of porous structures. Due to the 3-dimensional image provided by the large amount of reconstructed data obtained during the scanning, CT offers significant benefits over conventional radiographic testing [18]. Therefore, not only qualitative but also quantitative information can be acquired, such as the size and location of diverse pores and inclusions. Especially high-resolution scanning processes with voxel sizes in the range of micrometers $(\mu-\mathrm{CT})$ have become of increased significance [19]. Favretto et al. [20] conducted computer tomographic scanning to optimize a hybrid friction stir process combined with tungsten arc welding. During this study, $\mu$-CT has been confirmed as a powerful investigation tool for revealing internal defects such as pores. Dinda et al. [21] utilized $\mu$-CT scans for optimization of electron beam welded DP600 steel and Al 5754-joints. Based on the computed tomography, obtaining of the quantified information of weld defects was performed. It was discovered that the porosity formation is greatly dependent on different welding parameters such as beam oscillation. Teichmann et al. [22] performed a linear elastic finite element simulation of porous aluminum weldments based on voxel datasets acquired from $\mu$-CT analysis. The obtained scans provided a good basis for creating meshes describing the component integrity. Afterward, tensile testing of the probes was conducted. A good agreement between the simulation results and the real experiments was achieved, underpinning the feasibility of representing internal imperfections through $\mu$-CT acquisition.

\section{Materials and methods}

\subsection{Materials}

Considering applications in power electronics, the weld trials were carried out using $\mathrm{Cu}$-OFE (C10100) and Cu-ETP (CW004A) copper alloys. Basically, the Cu-OFE contains solely maximum of $5 \mathrm{ppm} \mathrm{O}_{2}$, mostly dissolved in the base material. In contrast, the residual $\mathrm{O}_{2}$ content of the $\mathrm{Cu}$-ETP is normally allowed up to $400 \mathrm{ppm}$, which leads to a decreased weldability. Due to the limited solubility of oxygen in copper at room temperature, these are located in the form of cuprous oxides at the grain boundaries. Hence, further challenges in welding such alloys lie in the oxygen 
Table 1 Nominal composition of the copper alloys [23, 24]

\begin{tabular}{llllllllll}
\hline \multicolumn{2}{l}{ Chemical composition $($ wt $\%)$} & \multicolumn{1}{l}{} \\
\hline Alloy & $\mathrm{Cu}$ & $\mathrm{O}$ & $\mathrm{Bi}$ & $\mathrm{Pb}$ & $\mathrm{S}$ & $\mathrm{Ag}$ & $\mathrm{Ni}$ & $\mathrm{Fe}$ \\
\hline Cu-OFE & $99.99<$ & $<0.005$ & $<0.0002$ & $<0.0005$ & $<0.0015$ & $<0.0025$ & $<0.001$ & $<0.001$ \\
Cu-ETP & $99.90<$ & $<0.04$ & $<0.0005$ & $<0.0005$ & - & - & - & - \\
\hline
\end{tabular}

Table 2 The solved gas contents of the alloys

\begin{tabular}{llll}
\hline \multicolumn{3}{l}{ Solved gas content $(\mathrm{ppm})$} \\
\hline Alloy & $\mathrm{H}$ & $\mathrm{N}$ & $\mathrm{O}$ \\
\hline Cu-OFE & 3.1 & $<10$ & 35 \\
Cu-ETP & 6.1 & $<10$ & 179 \\
\hline
\end{tabular}

gas and consequent porosity formation. However, on the ground of cost-effectiveness, the Cu-ETP alloys are particularly popular in the production of electrical components, and they therefore represent a significant application area. The nominal compositions of the used copper grades are shown in Table 1.

Additionally, dissolved oxygen, nitrogen, and hydrogen contents were measured by means of carrier gas hot extraction. The specimens underwent the same cleaning process (as described below) that was performed before the welding. The obtained values are presented in Table 2. Both alloys contain a very low amount of hydrogen. The nitrogen contents are located below the detection limit (10 ppm). In terms of oxygen content, the expected large difference is clearly noticeable. However, the $\mathrm{Cu}$-OFE specimen exhibits a higher content than the normative upper limit. It should be mentioned that these values refer to the examined specimen. A major feature of a thin wire-like structure is that it has a particularly large surface/volume ratio. Therefore, the oxide layer formed on the surface may strongly influence the obtained result. Although the specimens were cleaned, the oxide layer regenerates rapidly [25].

Figure 1 shows metallographic cross-sections extracted from a $\mathrm{Cu}$-OFE wire (a) as well as from a Cu-ETP wire (b and c). In the case of $\mathrm{Cu}$-ETP, two magnifications were used to ease the detection of the cuprous oxide, which is colored red under polarized light. As can be observed, the Cu-OFE is free from any precipitations. On contrary, evenly distributed cuprous oxides having up to $5 \mu \mathrm{m}$ in size were found in the microstructure of the $\mathrm{Cu}$-ETP specimens.

The rectangular wires used for the welding trials have a cross-section of $4.3 \times 2.33 \mathrm{~mm}$, resulting in an area of $10.02 \mathrm{~mm}^{2}$. All wires plugged in the welding jig had a length of $100 \mathrm{~mm}$. Before the welding sequence, the end of the wires was mechanically cleaned using polishing papers to fully remove the contamination as well as the undefined oxide layer formed during the storage.

\subsection{Electron beam welding}

The welding of the specimens was carried out using a highvacuum EBW machine (K26-3 by pro-beam, Gilching, Germany) with a maximal output power of $15 \mathrm{~kW}$. Since a high amount of metal vapor formation and therefore a slight increase of the vacuum pressure are to be expected when welding copper, the accelerating voltage was kept constant at $80 \mathrm{kV}$ to avoid flashovers in the beam generator. All welding trials were conducted with a working distance of $400 \mathrm{~mm}$ and under a static beam deflection, realizing an angle of incidence amounting to $4^{\circ}$ (see Fig. 2c). This step was inevitable to prevent the damage of the wire isolation at an unexpected occurrence of a non-zero gap, guaranteeing the beam absorption in the base material. To provide a sufficient clamping effect, the hairpins were placed into a welding jig that shows similarities with a stator, realizing

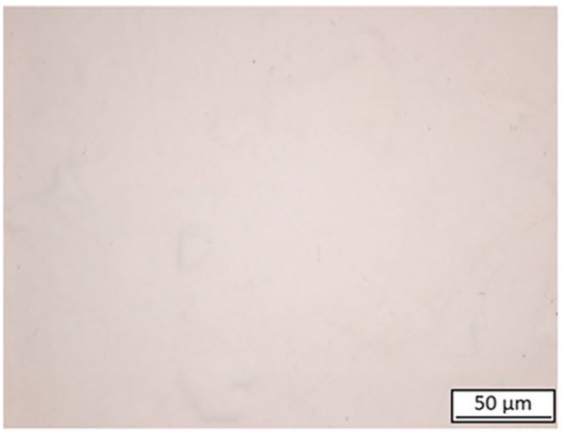

a)

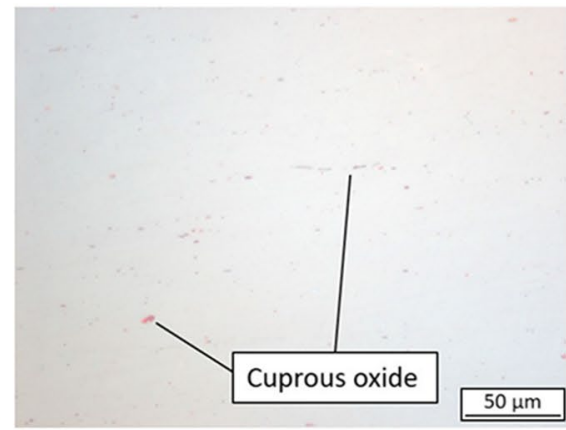

b)

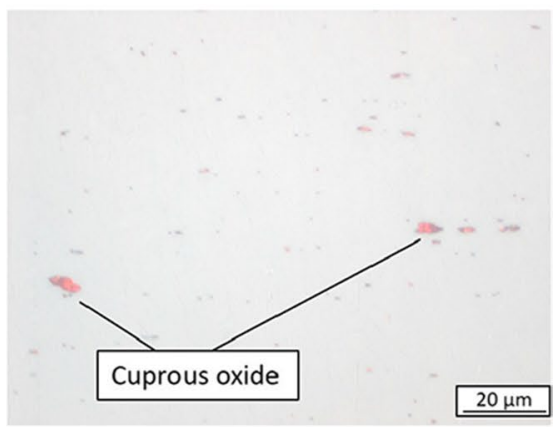

c)

Fig. 1 Metallographic cross-sections from a Cu-OFE (a) and a Cu-ETP base material (b, c) 


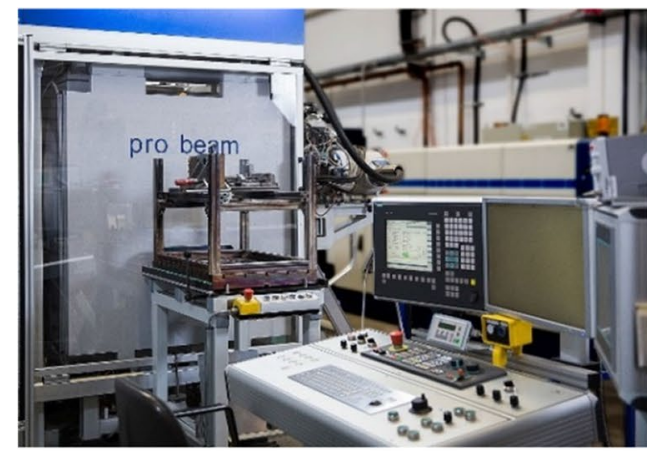

a)

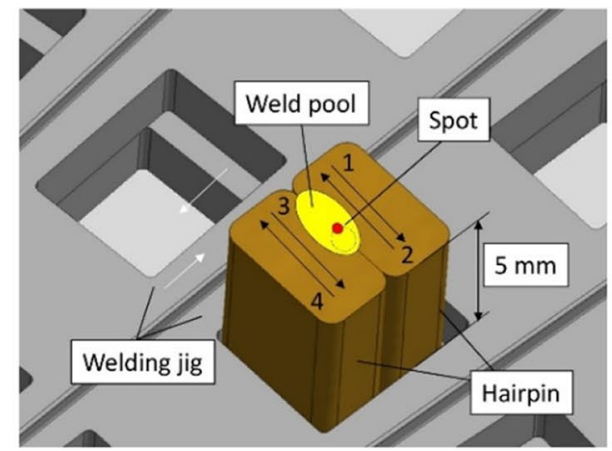

b)

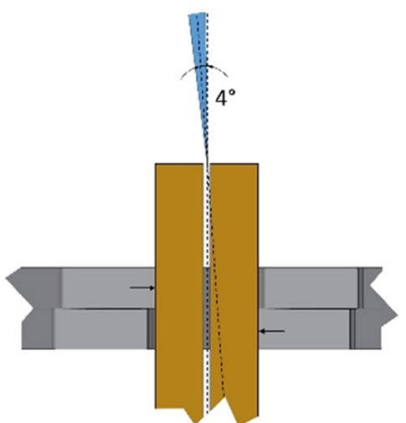

c)

Fig. 2 The electron beam welding machine (a), the schematic layout of the welding process (b), and the illustration of the incident beam in the case of a non-zero gap (c)

an application-oriented process. The welding jig utilizes a complex clamping mechanism so that the coincidence of the corresponding lateral faces of the hairpins can be maintained. A multiple overrun along the joint edge was chosen as the welding strategy, in which the inner edges of the hairpins were four-times welded in one sequence, using a circle as an oscillation figure with the respective frequencies and widths. Previous experiments showed that a lower number of passes often results in an asymmetric weld bead and also in a higher porosity. When welding materials susceptible to porosity formation, multiple remelting may become helpful as a large number of pores can be expelled through that, reducing the residual porosity [26]. The welding sequence was monitored using the build-in CCD camera of the EB machine and high-speed videography at $5000 \mathrm{fps}$, utilizing a coaxial light beam guidance. The welding machine used and the welding layout are depicted in Fig. 2.

\subsection{Methodical approach}

During the experimental design and the subsequent parameter optimization, the variation of the beam current, the focal distance, the welding length, the welding speed, and the beam oscillation parameters such as oscillation width and frequency took place. Due to the large number of technological variables and the complexity of the process, the parameter optimization was subdivided into three major stages, as shown in Fig. 3, with particular focus on the porosity as well as the joint cross-section area.
Hereby, the cross-section of the wire $(A)$ (as described in the Section 2.1) was considered as a basis (100\%). In order to prevent an increase in electrical resistance, the area of the joint cross-section must be at least as large as the wire crosssection. Based on statistical considerations, the following requirement can be formulated by Eq. (1):

$A \leq M-3 \sigma$

The $\mathrm{M}$ and $\sigma$ represent the mean area and the standard deviation of the joint cross-sections for a given parameter combination, respectively, which were determined based on the CT acquisition explained in Section 2.4. Using this requirement, $99.87 \%$ of the realized joints will fulfill the qualifications, assuming a Gaussian distribution of the joint cross-section.

Firstly, the investigation of beam oscillation was conducted by means of Design of Experiments (DoE) method, using a full factorial arrangement with two levels of each factor. Hereby, the welding length and the focal distance were kept as constant parameters, and the beam current $\left(I_{\mathrm{b}}\right)$, the oscillation frequency $(F)$, and width $(w)$ were varied based on the DoE arrangement. To fully understand the reason for porosity formation, both $\mathrm{Cu}$-ETP and $\mathrm{Cu}-\mathrm{OFE}$ were investigated, conducting three repetitions of each parameter combination. During the second step, the effect of over-focusing (focal point above the surface) was investigated in detail. In order to achieve a desired joint-cross section with low porosity, an optimal setting of focal distance should be determined. Based on the findings

\section{Investigation of beam oscillation parameters}

Fig. 3 The methodical approach of the parameter optimization 
Table 3 Welding parameters for the investigation of the beam parameters

\begin{tabular}{lllllll}
\hline $\begin{array}{l}\text { Parameter } \\
\text { number }\end{array}$ & $\begin{array}{l}\text { Beam cur- } \\
\text { rent }(\mathrm{mA})\end{array}$ & $\begin{array}{l}\text { Welding speed } \\
(\mathrm{mm} / \mathrm{s})\end{array}$ & $\begin{array}{l}\text { Weld length } \\
(\mathrm{mm})\end{array}$ & $\begin{array}{l}\text { Focal dis- } \\
\text { tance }(\mathrm{mm})\end{array}$ & $\begin{array}{l}\text { Oscillation fre- } \\
\text { quency }(\mathrm{Hz})\end{array}$ & $\begin{array}{l}\text { Oscillation } \\
\text { width }(\mathrm{mm})\end{array}$ \\
\hline $1-1$ & 33 & 40 & 2.8 & 15 & 100 & 0.8 \\
$1-2$ & 27 & 40 & 2.8 & 15 & 100 & 0.4 \\
$1-3$ & 27 & 40 & 2.8 & 15 & 1000 & 0.4 \\
$1-4$ & 27 & 40 & 2.8 & 15 & 100 & 0.8 \\
$1-5$ & 33 & 40 & 2.8 & 15 & 1000 & 0.8 \\
$1-6$ & 33 & 40 & 2.8 & 15 & 1000 & 0.4 \\
$1-7$ & 33 & 40 & 2.8 & 15 & 100 & 0.4 \\
$1-8$ & 27 & 40 & 2.8 & 15 & 1000 & 0.8 \\
$2-1$ & 27 & 35 & 2.4 & 15 & 1000 & 0.4 \\
$2-2$ & 27 & 35 & 2.4 & 10 & 1000 & 0.4 \\
$2-3$ & 27 & 35 & 2.4 & 5 & 1000 & 0.4 \\
$3-1$ & 27 & 38 & 2.6 & 10 & 1000 & 0.4 \\
\hline
\end{tabular}

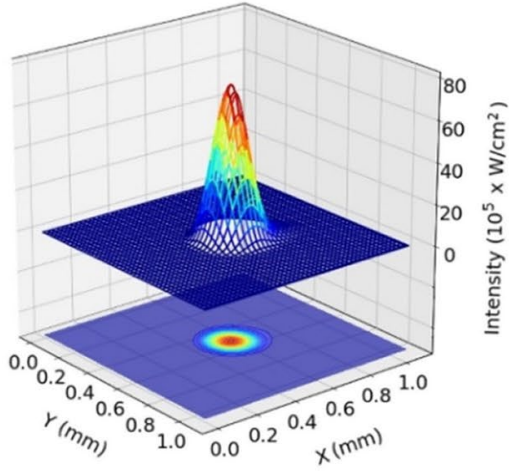

a)

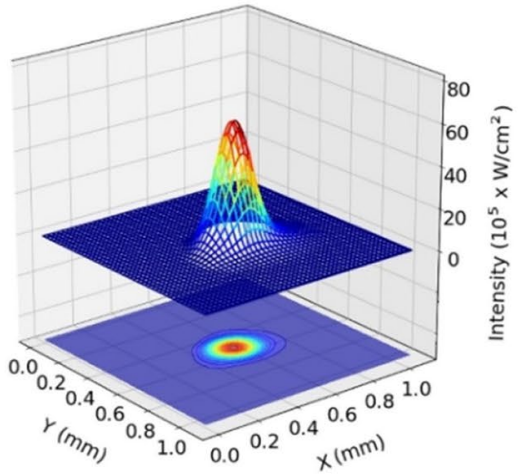

b)

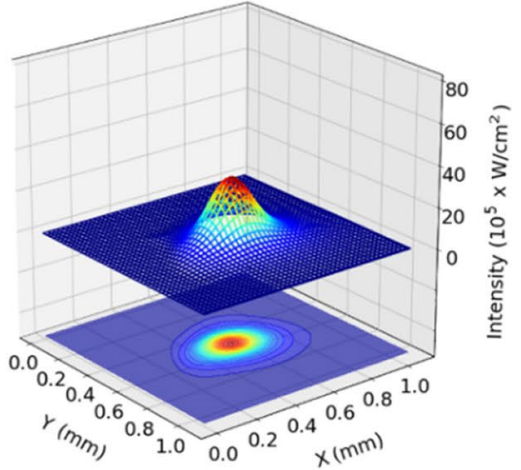

c)

Fig. 4 The profiles of the beam intensity at the working distance, using $5 \mathrm{~mm}$ (a), $10 \mathrm{~mm}$ (b), and $15 \mathrm{~mm}$ (c) over-focusing

observed in the previous step (see Section 3.1), the beam oscillation with $1000 \mathrm{~Hz}$ and $0.4 \mathrm{~mm}$ width was kept constant. The weld length was reduced from 2.8 to $2.4 \mathrm{~mm}$ in order to eliminate the spatter formation at the turning points of the weld path. Hence, the reduction of welding speed was also necessary to maintain an unaltered welding time and consequently the same energy input. As the porosity formation was the paramount issue in the case of deep penetration welding, only $\mathrm{Cu}$-ETP joints were welded. Five repetitions at each parameter combination were carried out. Table 3 contains the parameter combination applied during the process optimization.

In order to fully understand the effect of over-focusing, the electron beam profile was measured at the applied overfocusing distances using $27 \mathrm{~mA}$ beam current (since all further test runs took place using this setting), as presented in Fig. 4 . The beam diameter increases on the surface when using over-focusing, entailing also the change of the energy distribution.
Table 4 The investigated over-focusing distances and the corresponding beam parameters

\begin{tabular}{llll}
\hline $\begin{array}{l}\text { Over-focusing } \\
\text { distance }(\mathrm{mm})\end{array}$ & $\begin{array}{l}\text { Minimum beam } \\
\text { width }(\mu \mathrm{m})\end{array}$ & $\begin{array}{l}\text { Maximum beam } \\
\text { width }(\mu \mathrm{m})\end{array}$ & Ellipticity $(-)$ \\
\hline 5 & 260 & 290 & 0.89 \\
10 & 260 & 330 & 0.79 \\
15 & 360 & 490 & 0.73 \\
\hline
\end{tabular}

Based on the measured beam profiles, the beam widths, as well as the ellipticity values, were determined, as shown in Table 4. Here, the minimum and maximum beam widths refer to the $1 / \mathrm{e}^{2}$ widths [27] along the corresponding principal axis, considering the spot as an ellipse. As the angle $(\varphi)$ between the axes of the laboratory coordinate system ( $x$ and $y$ ) and the respective principal axes of the beam is smaller than $5^{\circ}$ (hence $\sin \varphi=\varphi$ can be assumed) in all cases, the minimum and the maximum beam widths correspond to the 
beam width in the $y$-direction and the $x$-direction, respectively. As it seems, the beam greatly expands when using over-focusing, especially along the $x$ axis, which is parallel to the welding direction.

Finally, based on the previous results described in the Section 3.1, a small parameter adjustment was performed for maintaining a low porosity and achieving the desired crosssectional area of the joint. The weld length and the welding speed were increased to $2.6 \mathrm{~mm}$ and $38 \mathrm{~mm} / \mathrm{s}$, respectively. Hereby, five repetitions of $\mathrm{Cu}$-ETP and three repetitions of $\mathrm{Cu}$-OFE were welded to provide a complete comparison.

\subsection{X-ray computed tomography}

The X-ray computed tomography (CT) was performed using a $\mu$-CT (Vtomex by General Electric, Boston, USA) scanner. Table 5 gives a detailed overview of the applied machine parameters.

Based on the CT images, manual image analysis was used to determine the joint cross-section as depicted on Fig. 5. This is based on the fact that the fusion line is slightly noticeable, thus enables the calculation of the cross-sectional area. The validation of this method was then performed based on metallographic cross-sections. Furthermore, a porosity analysis on the whole volume was conducted. The porosity analysis compares the obtained grey values of the respective voxels to that of their local environment. Differences in the grey values occur due to the reduced $\mathrm{X}$-ray absorption of the gas pores compared to the base metal. During the procedure, deviating regions having at least a volume of 8 voxels were considered as a pore. This is based on previous experiences gained by analyzing porous materials. Setting this limit on lower numbers (e.g., 1 or 4) may increase the risk that voxels having a noise will be identified as a pore by mistake (noiseinduced pores). In many industrial applications, this limit is chosen between 8 and 27 [28-30]. The analysis focused furthermore on the volume determination as well as the sphericity calculation of the individual pores. By summing the individual volumes, the total porosity can also be obtained. Sphericity $(\psi)$, as defined by Waddel [31], is the ratio of the surface area of an equal-volume sphere to the actual surface area of the pore. This is expressed in Eq. (2):

$\psi=\frac{\pi^{\frac{1}{3}}\left(6 V_{\text {Pore }}\right)^{2 / 3}}{A_{\text {Pore }}}$

where $V_{\text {Pore }}$ and $A_{\text {Pore }}$ stand for the volume and the surface of the pore, respectively.

In order not to consider the pores as a conductive region of the material, if severe porosity occurred, a subsequent binarization was carried out on the $2 \mathrm{D}$ sections, using a custom-made algorithm in Python 3.7 and openCV to label the pores and additionally extract them from the gross area of the joint. This ended in the determination of the net joint cross-section related to the wire cross-section; the results of which are presented in the Section 3.

\subsection{Metallographic investigations}

Subsequent to the welding and the X-ray computed tomography, the specimens chosen for further investigation underwent additional metallographic examinations. After cutting off the top of the hairpins, the cross-sections were ground and polished, followed by etching with $\mathrm{Cu} \mathrm{m} 1$

Table 5 The applied settings of the CT measurements

\begin{tabular}{lllllll}
\hline $\begin{array}{l}\text { Image number per } \\
\text { scan }(-)\end{array}$ & $\begin{array}{l}\text { Accelerating } \\
\text { voltage }(\mathrm{kV})\end{array}$ & Beam current $(\mu \mathrm{A})$ & Exposure time $(\mathrm{ms})$ & $\begin{array}{l}\text { Source to sample } \\
\text { distance }(\mathrm{mm})\end{array}$ & $\begin{array}{l}\text { Source to detector } \\
\text { distance }(\mathrm{mm})\end{array}$ & $\begin{array}{l}\text { Voxel size }(\mu \mathrm{m}) \\
1441\end{array}$ \\
\hline 200 & 60 & 600 & 45 & 800 & 11.0 \\
\hline
\end{tabular}
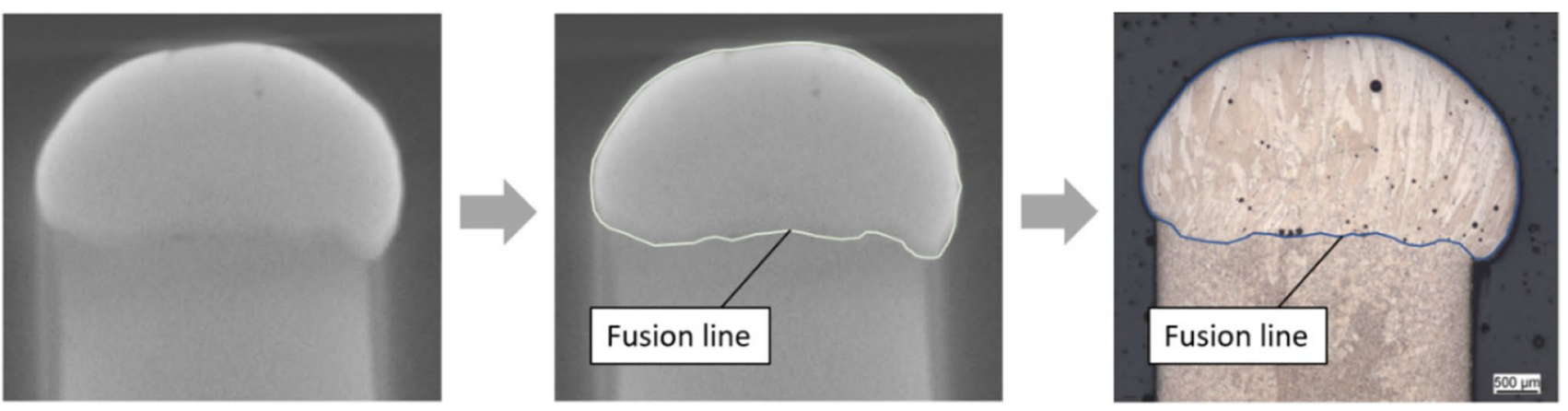

Fig. 5 Evaluation and subsequent validation of the joint cross-section area by means of CT imaging and metallographic investigations 
(according to Petzow). Hereby, transversal (cutting plane coincident with the gap) and longitudinal (cutting plane perpendicular to the gap) cross-sections were investigated, as depicted in Fig. 6. The transversal cross-sections were used to validate the shape and the area of the joint-cross sections so that the remaining specimens could be reliably evaluated without the need for metallographic preparations at all probes. On the contrary, the longitudinal sections provide information about the general quality of the connection. Furthermore, the shape of the weld seam can also be analyzed in detail.

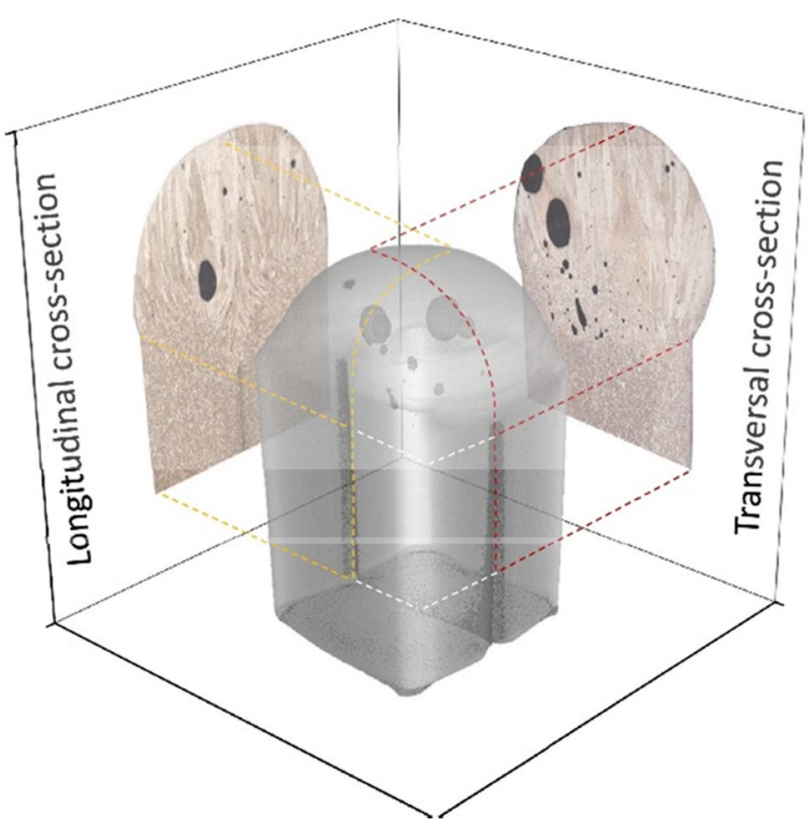

Fig. 6 Sematic illustration of the positions of transversal and longitudinal cross-sections

\section{Results}

\subsection{Effects of beam parameters on the porosity and joint-cross section}

After the welding of the specimens, all probes underwent CT scanning. Figure 7 shows some CT results performed on $\mathrm{Cu}$-OFE probes. Having no residual oxygen in the matrix allows the welding with a wide range of parameter combinations without occurring notable pores. Since only very low, sporadic porosity was observed during the analysis of all results, no further quantitative analysis was conducted.

As a result of the residual oxygen content, the Cu-ETP connections show significant porosity, depending on the applied beam oscillation parameters and the current, as shown in Fig. 8. Weldments, which are realized with the lower level of current, applying high-frequency beam oscillation with small width exhibit the lowest amount of total porosity (combination 1-3, see Table 3 ). In contrast to that, inappropriate beam oscillation, especially combined with higher currents, results in joints showing an excessive pore amount. Furthermore, pore accumulation can be observed at high porosity, often forming large coalesced pores frequently in the middle of the weld metal.

For further process evaluation, the qualitative monitoring of the weld pool behavior was performed (see Fig. 9) based on high-speed recordings. Using low oscillation frequencies (i.e., $100 \mathrm{~Hz}$ ), a resonance and a consequent sloshing of the molten metal can be observed. In contrast, using high frequencies (e.g., $1000 \mathrm{~Hz}$ ) promotes the steady behavior of the weld pool.

For further optimization, the focal distance was varied as described in Section 2.3, using the beam oscillation parameters and the beam power which have previously proven to be the most expedient.

Figure 10 presents the $\mathrm{CT}$ scans of the $\mathrm{Cu}$-ETP hairpin pairs created with different over-focusing (f) parameters.
Fig. 7 CT-scans of Cu-OFE hairpin pairs welded with different parameter combinations ((a) 1-3; (b) 1-2; (c) 1-4; and (d) 1-5)

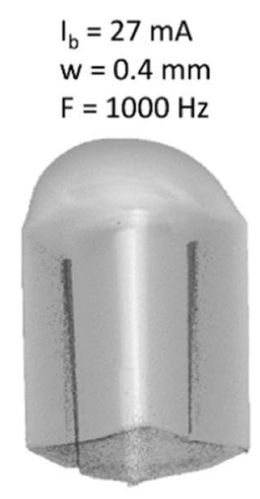

a)

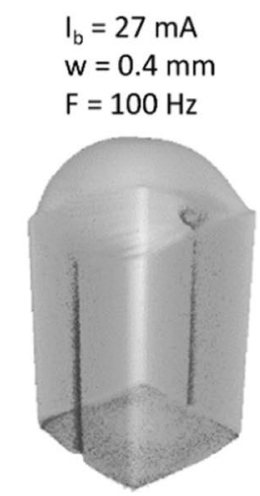

b)

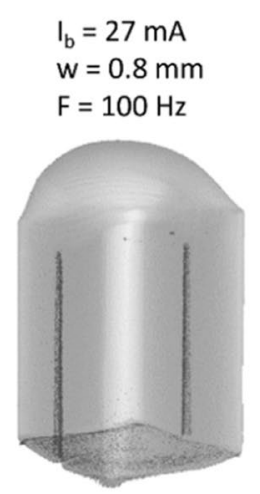

c)

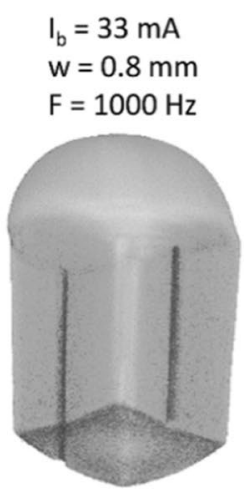

d) 


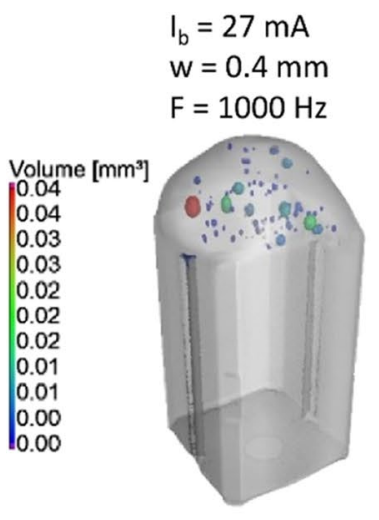

a)

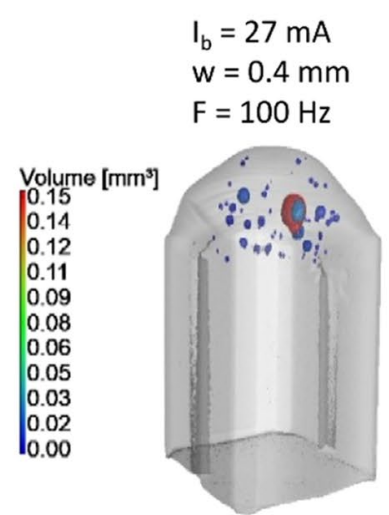

b)

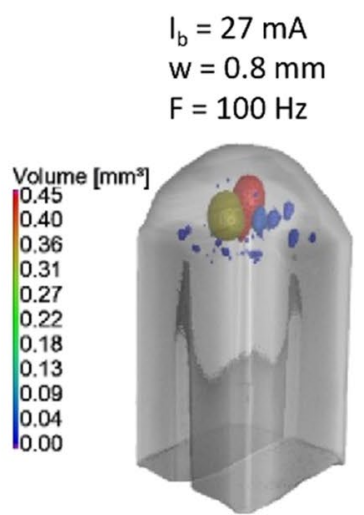

c)

$$
\begin{aligned}
& \mathrm{I}_{\mathrm{b}}=33 \mathrm{~mA} \\
& \mathrm{~W}=0.8 \mathrm{~mm} \\
& \mathrm{~F}=1000 \mathrm{~Hz}
\end{aligned}
$$
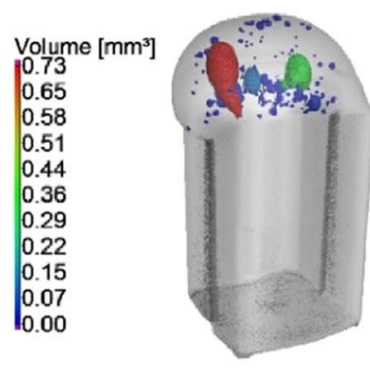

d)

Fig. 8 CT-scans of Cu-ETP hairpin pairs welded with different parameter combinations ((a) 1-3; (b) 1-2; (c) 1-4; and (d) 1-5)
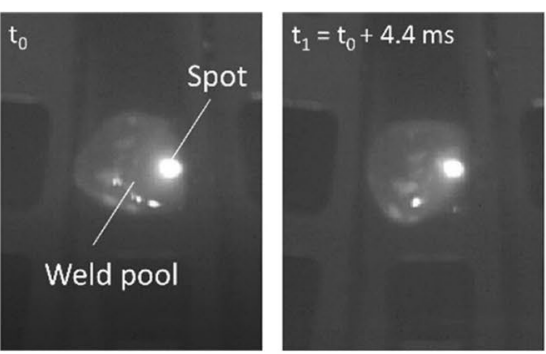

a)
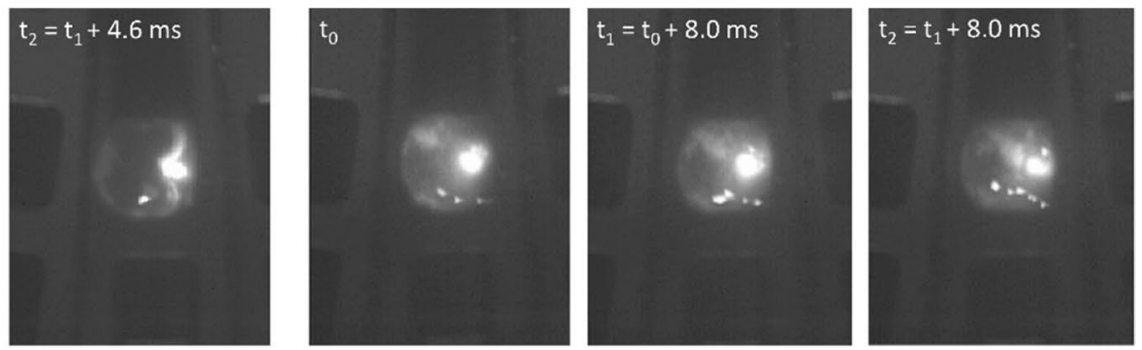

b)

Fig. 9 Slow motion recording in the case of $100-\mathrm{Hz}$ (a) and 1000-Hz (b) oscillation frequencies, using in both cases 0.4-mm oscillation diameter

Fig. 10 CT-scans of Cu-ETP hairpin pairs welded with different parameter combinations ((a) $2-1$; (b) 2-2; and (c) 2-3)

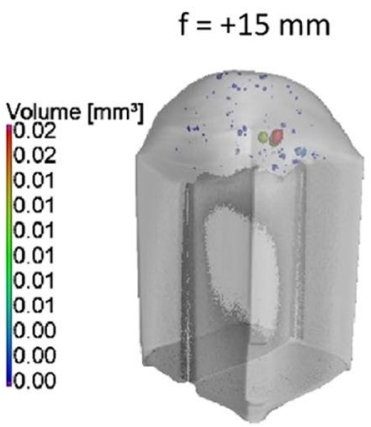

a)

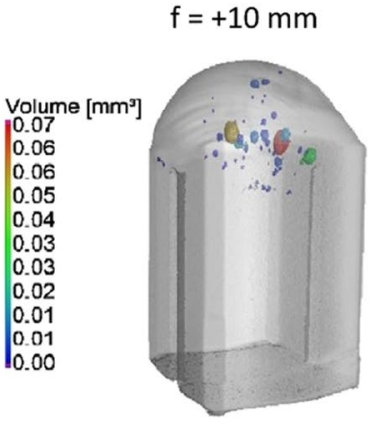

b)

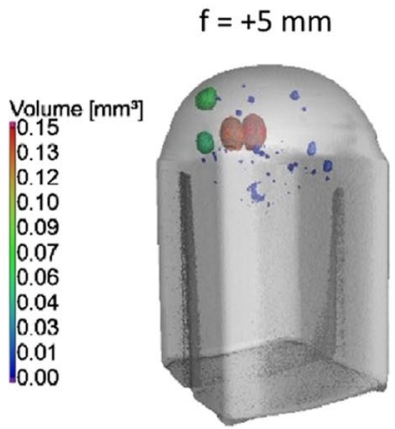

c)
With increasing focusing (from left to right), the porosity unambiguously increases. Although, so does the penetration depth and consequently the joint-cross section, which allows the reduction of the beam current and hence the thermal load if a given joint cross-sectional area is striven. Therefore, a compromise was sought.

\subsection{Porosity analysis of the optimized joints}

Based on the results discussed in Section 4, it can be stated that $10 \mathrm{~mm}$ over-focusing distance can be viewed as a compromise. It leads to only a tiny loss of the jointcross section, but results in a great reduction of porosity 


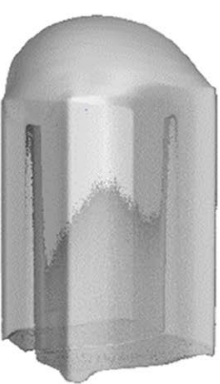

a)

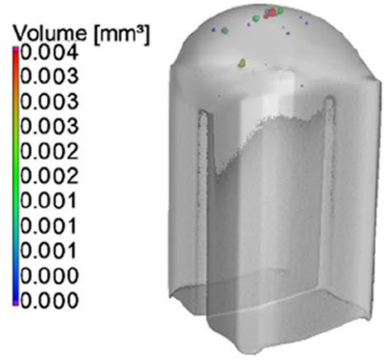

b)

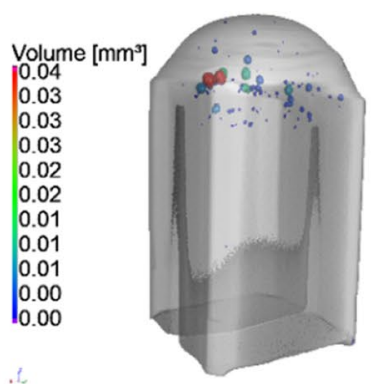

c)

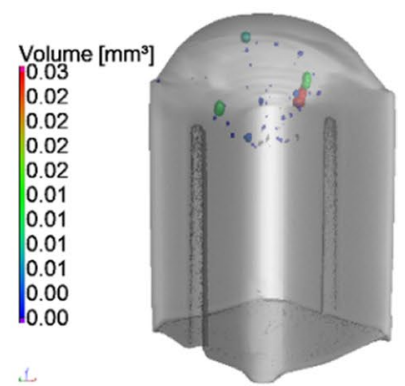

d)

Fig. 11 CT-scans of Cu-OFE (a, b) and Cu-ETP (c, d) hairpin pairs, applying the final parameters (3-1)

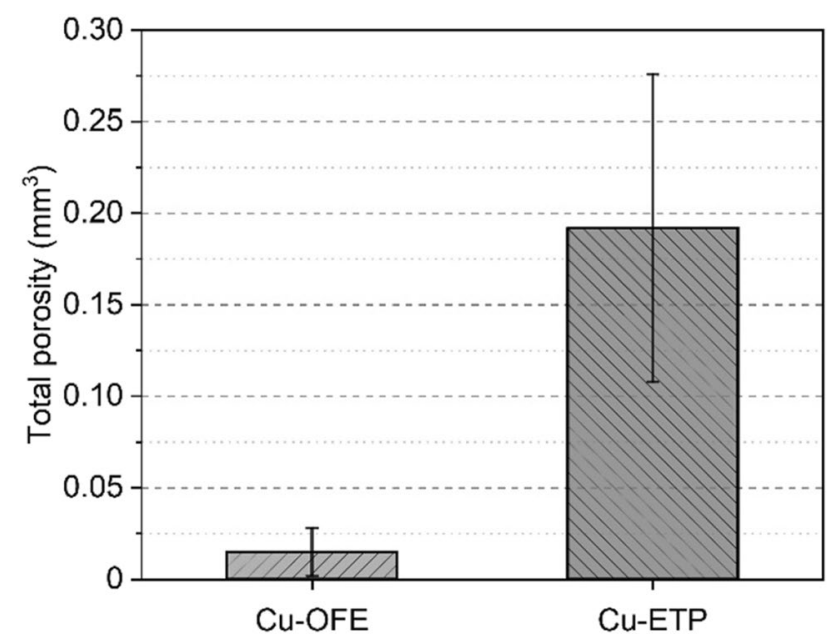

Fig. 12 Comparison between the $\mathrm{Cu}-\mathrm{OFE}$ and $\mathrm{Cu}-\mathrm{ETP}$ joints in terms of total porosity, using the final parameter combination (3-1)

compared to the setting using $5 \mathrm{~mm}$ over-focusing. Comparing to the setting applying $15 \mathrm{~mm}$ over-focusing, a significant increase in the joint cross-section can be achieved, having only slightly higher porosity (see Fig. 18). Conducting further small optimization steps, an optimized parameter combination (3-1) was developed to achieve a joint with sufficient cross-sectional area as well as moderate porosity. As previously discussed in Section 2, altogether five repetitions were welded in the case of Cu-ETP. For the sake of completeness, three hairpins made of $\mathrm{Cu}-$ OFE were also welded for comparison. During the welding process, no spatter formation was detected. The average joint cross-sectional area of the Cu-ETP joints amounts to $113 \pm 3 \%$; therefore, it can be stated that a process with excellent robustness was achieved. As shown in Fig. 11, the $\mathrm{Cu}$-OFE probes normally have no or only a very low amount of porosity, as was already the case in the initial state of the experiments (see Fig. 7). In contrast, the parameter optimization at the Cu-ETP specimens greatly contributed to reduction of the porosity, while also achieving the desired joint cross-section. The reduced amount of porosity becomes more obvious when compared to that obtained in the initial stage of the study (see Fig. 8).

Figure 12 presents the quantitative comparison of the total porosity between the $\mathrm{Cu}-\mathrm{OFE}$ and $\mathrm{Cu}$-ETP probes, applying the same welding parameters. Based upon the results, it can be stated that the residual oxygen content remains the most decisive factor despite the optimization of the weld parameters.

Table 6 contains the results obtained from the porosity analysis of the $\mathrm{Cu}$-ETP probes. Here, by analyzing the mean values of the sphericity, it can be stated that the acquired pores are mostly round and thus a result of gas formation. These values are comparable with other previous works [32], which also dealt with gas-induced porosity. Considering the almost porosity-free $\mathrm{Cu}-\mathrm{OFE}$ joints, a keyhole instability as a possible reason for porosity can be excluded. As the hydrogen and the nitrogen contents are also below $10 \mathrm{ppm}$, their contribution to the pore formation through development of steam or nitrogen-oxides can also be ruled out. Solely the difference in the oxygen contents can be considered as a possible reason. Even though in both cases a considerable amount of oxygen is solved
Table 6 Results of the porosity analysis on the $\mathrm{Cu}$-ETP specimens. Data from 5 repetitions (Rep.)

\begin{tabular}{llllll}
\hline & Rep. 1 & Rep. 2 & Rep. 3 & Rep. 4 & Rep. 5 \\
\hline Number of pores $(-)$ & 77 & 112 & 87 & 49 & 77 \\
Total porosity $\left(\mathrm{mm}^{3}\right)$ & 0.204 & 0.198 & 0.145 & 0.071 & 0.336 \\
Maximal pore volume $\left(\mathrm{mm}^{3}\right)$ & 0.034 & 0.059 & 0.036 & 0.026 & 0.101 \\
Mean pore sphericity $(-)$ & $0.61 \pm 0.05$ & $0.59 \pm 0.04$ & $0.58 \pm 0.07$ & $0.56 \pm 0.06$ & $0.59 \pm 0.07$ \\
\hline
\end{tabular}


in the weld pool through the oxide layer, the difference is still great (a factor of five-six), as presented in Table 2.

Furthermore, the individual pores were analyzed with particular focus on the pore volume as well as its distribution. Since only a few sporadic pores were detected in the case of oxygen-free copper, a boxplot chart was created solely for the Cu-ETP probes, as depicted in Fig. 13a. It can be clearly observed that the majority of pores exhibit a volume between $0.05 \times 10^{-3}$ and $5 \times 10^{-3} \mathrm{~mm}^{3}$ at all repetitions. It can be therefore stated that weldments with low total porosity and finely distributed small pores were realized. Figure $13 \mathrm{~b}$ reveals the sphericity values of each pore, providing information about their morphology. A decreasing trend of the sphericity values with the increase of the pore volume can be clearly seen. This shows a good agreement with previous results reported by other authors $[17,33]$. The very small pores having a diameter below roughly $25 \mu \mathrm{m}$ (equivalent to a volume of $0.008 \times 10^{-3} \mathrm{~mm}^{3}$ ) cannot be detected due to the applied voxel size. In this case, higher sphericity values would have been expected, as they tend to have a more round form based on the above-cited publications. The larger the pores, the more likely is that surface irregularities occur, which results in a decreased sphericity value.

In Fig. 14, metallographic cross-sections of one Cu-OFE (a) and two Cu-ETP joints (b, c) are presented. In the case of the oxygen-free copper grade, only two very small pores were detected in the section plane. When welding $\mathrm{Cu}$-ETP, a low amount of porosity can be observed. In contrast to the results obtained in the early stages of the research, no large coalesced pores occur. Instead, there are smaller pores evenly distributed in the matrix. In addition, symmetric weld seams were realized without any cracks or further internal imperfections.

\section{Discussion}

In terms of porosity, the adequate combination of oscillation frequency, oscillation width, and beam current has proven to be the most determining factor when Cu-ETP is being discussed. Two heat map plots with the qualitative description of the porosity are depicted in Fig. 15. Darker colors indicate a severe porosity where large coalesced pores are common. The brighter the color, the lower the amount of porosity.

A possible explanation for this is the influencing of the weld pool dynamics, which is responsible for the modification of the degassing conditions. Furthermore, it has been revealed that a resonance of the weld pool (which occurs at $100 \mathrm{~Hz}$ oscillation frequency) should be preferably avoided. On the one hand, if it occurs, the risk of spatter formation increases, especially at the turning points of the weld path.
Fig. 13 The porosity distribution (a) and the obtained sphericity values in the function of the pore volume (b) in the case of $\mathrm{Cu}$-ETP weldments

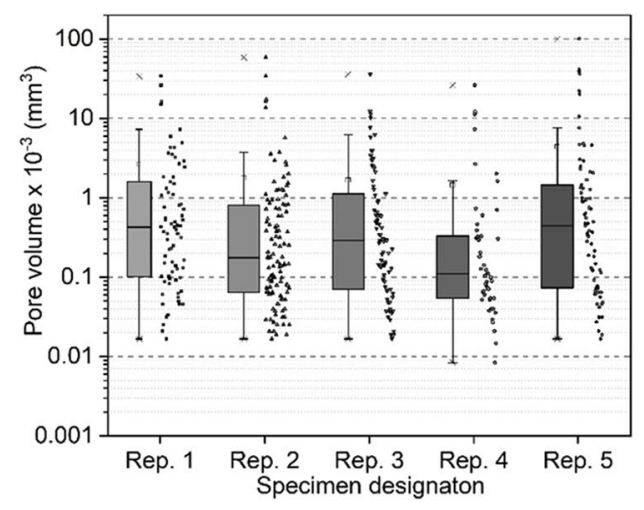

a)

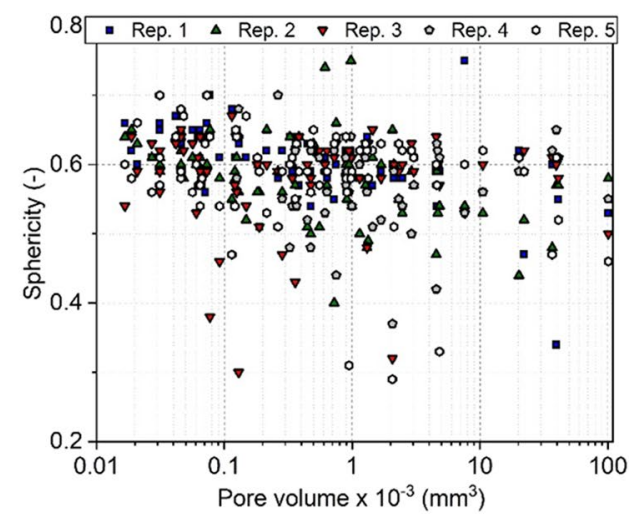

b)
Fig. 14 Cross-sections of the electron beam welded $\mathrm{Cu}$-OFE (a) and $\mathrm{Cu}-\mathrm{ETP}(\mathrm{b}, \mathrm{c})$ hairpin pairs

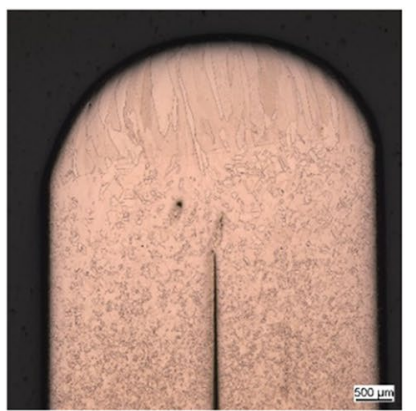

a)

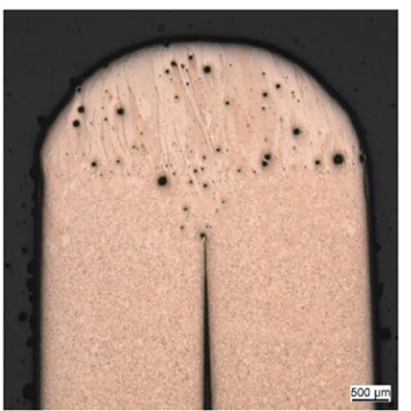

b)

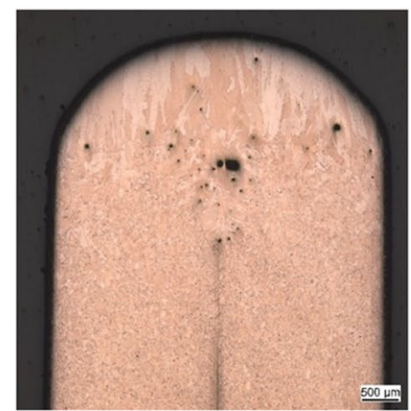

c) 
Fig. 15 Influence of the beam oscillation parameters on the porosity at $27-\mathrm{mA}$ (a) and 33-mA (b) beam currents when welding $\mathrm{Cu}$-ETP hairpins

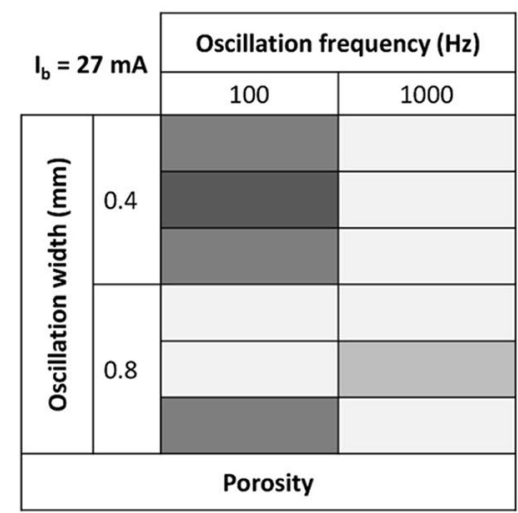

a)

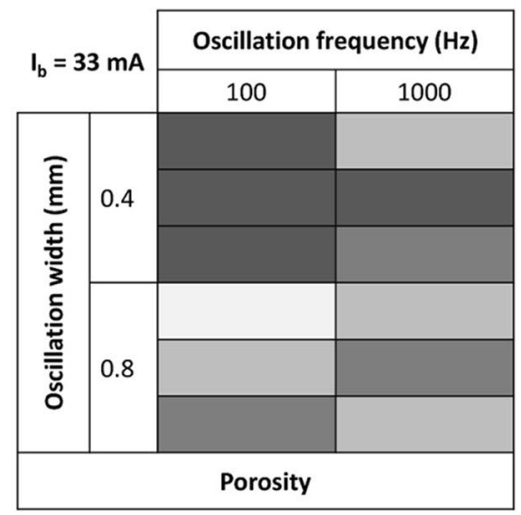

b)

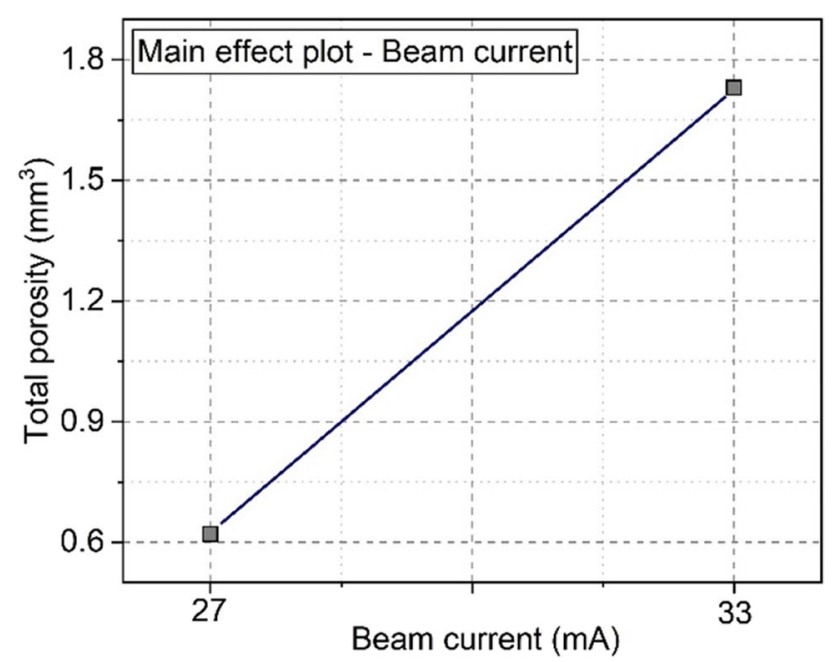

Fig. 16 Main effect plot of the beam current on the total porosity

On the other hand, the unsteady behavior may lead to hindered degassing under certain conditions (e.g., combined with $0.4 \mathrm{~mm}$ oscillation width), increasing the number of pores being entrapped in the weld metal. In terms of porosity, not only the beam oscillation parameters but also the beam current are of importance. To find a quantitative relationship between the beam current and the total amount of porosity, the main effect of the beam current was evaluated based on the results of the full-factorial DoE, as illustrated in Fig. 16. The generated main effect plot (which graphs the response mean for each factor level [34]) clearly depicts the beam current dependence of the total porosity when welding $\mathrm{Cu}$-ETP. An explanation for this is the increasing volume of the molten metal when welding with a higher power. This leads to a higher amount of solved oxygen in the weld pool, as its main source is the base metal, resulting in higher residual porosity after the solidification. Furthermore, higher beam currents are linked with deeper penetrations, making the degassing more difficult. Therefore, only a minimum required level of beam current should be used to keep the molten volume and the excessive penetration under control.

The beam current and the oscillation parameters are not only decisive for the porosity, but also for the penetration depth and thus for the area of the joint crosssection. Figure 17 reveals the main effects of the beam current as well as the beam oscillation width on the joint cross-sectional area of the Cu-ETP specimens. In terms of joint cross-section, no significant difference was detected between the $\mathrm{Cu}$-ETP and $\mathrm{Cu}$-OFE probes. Using higher
Fig. 17 Main effect plots of the beam current (a) and the beam oscillation width (b) on the joint-cross section

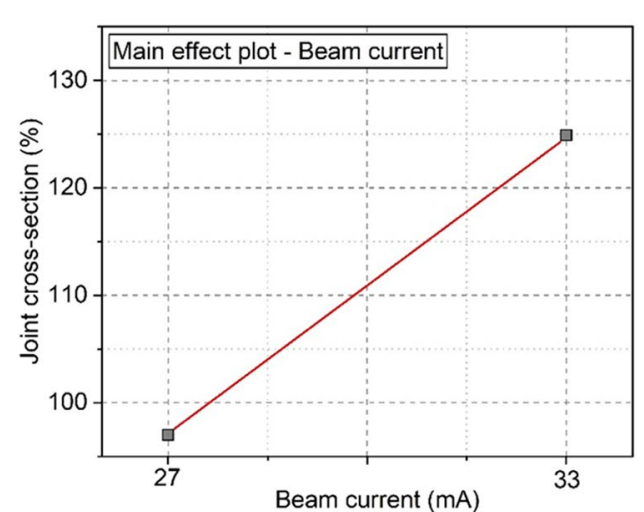

a)

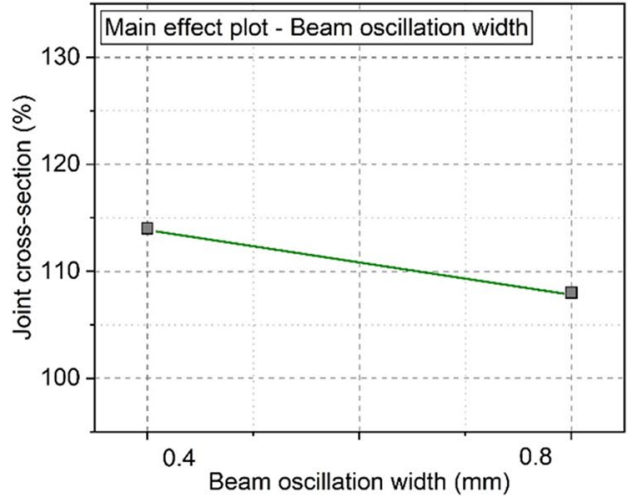

b) 
beam currents, a steep rise of the penetration and consequently the area of the cross-section can be observed. However, increased beam current levels became apparent to result in higher porosity. In terms of beam oscillation, a slight drop occurs when applying higher oscillation widths. As a result of larger oscillation patterns, a decreased energy is concentrated on the joint edge, causing a slight decrease in the cross-section. Furthermore, increased oscillation width often led to spatter formation at the turning points at the weld path (see Figure 2) attributed also to the excessive weld length. Albeit the beam did not leave the part in that case, the process still can be unstable as the liquid metal partially hangs out over the edge. In addition, the oscillation frequency was discovered to have no demonstrable influence on the penetration depth over the investigated parameter range.

Figure 18 shows the alteration of the joint cross-section and the amount of porosity as a function of the overfocusing distance. Striking in this chart is the quadratic decrease of the joint cross-section with increasing overfocusing. Increased defocusing leads to a smaller amount of porosity. Since these parameters are located near the optimum and the amount of the porosity is already low, an increased relative error in terms of total porosity can be observed. Hence, solely a decreasing trend can be clearly determined. As an explanation, the increased spot size can be considered, as applying higher over-focusing distances (reducing the focal distance with unaltered welding setup) results in a greater beam diameter and thus in a wider seam with shallower weld penetration attributed to the reduced deep welding effect. This results in an enlarged weld pool surface, supporting the degassing of the molten copper. Moreover, the decreased deep welding effect and the resulting wider and shallower keyhole reduce the risk that pores are being entrapped in the cavity, improving the degassing before the solidification occurs.

\section{Conclusions}

The electron beam technologies offer numerous advantages when welding copper alloys. Due to the interaction between the electrons and the solid body, no reflection of the incident beam occurs. The high flexibility of the process allows the precise adjustment of the energy distribution and thus the targeted modification of the penetration depth as well as the weld shape. Furthermore, the dynamic beam oscillation can effectively influence the weld pool behavior and the consequent degassing during the welding. The goal of the current study was the detailed investigation of porosity formation in welding of rectangular copper wires applied in electrical drives. Based on the welding trials and the subsequent analysis, the following conclusions are drawn:

- The main reason for the porosity formation is the residual oxygen content of the base material. The amount of dissolved oxygen decreases rapidly below the solidus temperature, forming gas pores in the weld metal. When welding oxygen-free copper grades, a wide range of parameters can be used without porosity occurring.

- Since no significant porosity can be observed in the case of Cu-OFE welding, independent from the beam oscillation parameters, it can be stated that no sudden collapse of the keyhole takes place. Furthermore, the analysis of the pore sphericity underpins the fact that solely the gas formation is responsible for the porosity over the investigated parameter range.

- When welding copper grades with high residual oxygen content, the adequate combination of beam oscillation frequency and width is the most essential step, providing good degassing conditions.

- Elevation of the beam current results in increased porosity formation due to the enlarged fraction of molten state, as the main source of oxygen is the base material.
Fig. 18 The joint cross-section (a) and the porosity (b) in dependence of the over-focusing distance

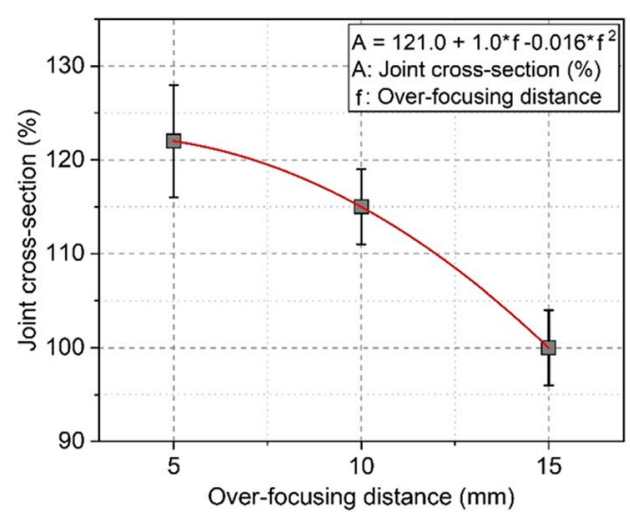

a)

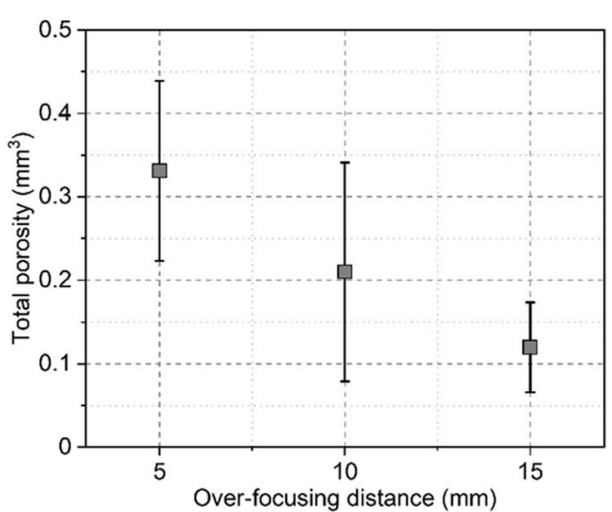

b) 
- Welding in focus or slightly focused above the surface entails the risk of root porosity formation, since the pores cannot escape from the narrow and deep weld seam. Increased over-focusing reduces the amount of pores.

- Excessive focusing above the surface strongly reduces the penetration depth.

Supplementary Information The online version contains supplementary material available at https://doi.org/10.1007/s40194-021-01158-4.

Acknowledgements The authors would like to express their appreciation for the technical support provided by pro-beam GmbH \& Co. $\mathrm{KGaA}$ and pro-beam systems $\mathrm{GmbH}$.

Author contribution T. Tóth: Conceptualization, formal analysis, investigation, methodology, visualization, writing — original draft.

J. Hensel: Conceptualization, data curation, project administration, supervision, validation, writing - review and editing.

S. Thiemer: Conceptualization, methodology, supervision, validation

P. Sieber: Conceptualization, methodology, validation.

K. Dilger: Funding acquisition, resources, supervision.

All authors have read and agreed to the published version of the manuscript.

Funding Open Access funding enabled and organized by Projekt DEAL. The authors acknowledge support by the Open Access Publication Funds of Technische Universität Braunschweig. This research was funded by the Dobeneck-Technologie-Stiftung.

Availability of data and material The raw/processed data required to reproduce these findings cannot be shared at this time due to time limitations.

\section{Declarations}

Conflict of interest The authors declare no competing interests.

Open Access This article is licensed under a Creative Commons Attribution 4.0 International License, which permits use, sharing, adaptation, distribution and reproduction in any medium or format, as long as you give appropriate credit to the original author(s) and the source, provide a link to the Creative Commons licence, and indicate if changes were made. The images or other third party material in this article are included in the article's Creative Commons licence, unless indicated otherwise in a credit line to the material. If material is not included in the article's Creative Commons licence and your intended use is not permitted by statutory regulation or exceeds the permitted use, you will need to obtain permission directly from the copyright holder. To view a copy of this licence, visit http://creativecommons.org/licenses/by/4.0/.

\section{References}

1. Riedel A, Masuch M, Weigelt M, Gläßel T, Kühl A, Reinstein, S, Franke J (2018) Challenges of the hairpin technology for production techniques. In Proceedings of the 21st International Conference on Electrical Machines and Systems (ICEMS), Jeju pp 2471-2476. https://doi.org/10.23919/ICEMS.2018.8549105
2. American Welding Society (2007) AWS welding handbook volume 4: metals and their weldability. Chapter 7: Copper Alloys p 274

3. American Welding Society (1997) AWS welding handbook volume 3: materials and applications. Chapter 3: Copper and Copper Alloys p 177

4. Auwal S, Ramesh S, Yusof F, Manladan S (2018) A review on laser beam welding of copper alloys. Int J Adv Manuf Technol 96:1-16. https://doi.org/10.1007/s00170-017-1566-5

5. Weman K (2003) Welding processes handbook. Woodhead Publishing, Cambridge

6. Biro E, Weckman D, Zhou Y (2002) Pulsed Nd:YAG laser welding of copper using oxygenated assist gases. Metall Mater Trans A 33:2019-2030. https://doi.org/10.1007/s11661-002-0034-4

7. Svenungsson J, Choquet I, Kaplan A (2015) Laser welding process - a review of keyhole welding modelling. Phys Procedia 78:182-191. https://doi.org/10.1016/j.phpro.2015.11.042

8. Zhang L-J, Zhang G-F, Ning J, Zhang X-J, Zhang J-X (2015) Microstructure and properties of the laser butt welded 1.5-mm thick T2 copper joint achieved at high welding speed. Mater Des 88:720-736. https://doi.org/10.1016/j.matdes.2015.09.072

9. Zhang L-J, Bai Q-L, Ning J, Wang A, Yang J-N, Yin X-Q, Zhang $\mathrm{J}$-X (2016) A comparative study on the microstructure and properties of copper joint between MIG welding and laser-MIG hybrid welding. Mater Des 110:35-50. https://doi.org/10.1016/j.matdes. 2016.07.117

10. Hess A, Schuster R, Heider A, Weber R, Graf T (2011) Continuous Wave laser welding of copper with combined beams at wavelengths of $1030 \mathrm{~nm}$ and of $515 \mathrm{~nm}$. Phys Procedia 12:88-94. https://doi.org/10.1016/j.phpro.2011.03.012

11. Chung W-S, Olowinsky A, Gillner A (2020) Process studies on copper laser beam welding over gap by using disc laser at green wavelength. J Adv Join Process 1:100009. https://doi.org/10. 1016/j.jajp.2020.100009

12. Horrigan VM (1977) The solubility of oxygen in solid copper. Metall. Trans. A 8:785-787. https://doi.org/10.1007/BF02664788

13. Friedrich B, Kräutlein C, Krone K (2006) Melt treatment of copper and aluminium - the complex step before casting. In Proceedings of the international conference on continous casting of nonferrous metals, Wiley-Vch, DGM pp 3-22

14. Olson DL, Siewert TA, Liu S, Edwards GR (1993) ASM handbook vol. 6: welding, brazing and soldering. Electron-Beam Welding pp 740-755

15. Johnson LD (1970) Some observations on the electron beam welding of copper. Weld J 49:55-60

16. Kanigalpula PKC, Jaypuria S, Pratihar DK, Jha MN (2018) Experimental investigations, input-output modeling, and optimization of spiking phenomenon in electron beam welding of ETP copper plates. Measurement 129:302-318. https://doi.org/10.1016/j. measurement.2018.07.040

17. Kar J, Dinda SK, Roy GG, Roy SK, Srirangam P (2018) X-ray tomography study on porosity in electron beam welded dissimilar copper-304SS joints. Vacuum 149:200-206. https://doi.org/10. 1016/j.vacuum.2017.12.038

18. Maire E, Withers PJ (2014) Quantitative X-ray tomography. Int Mater Rev 59(1):1-43. https://doi.org/10.1179/1743280413Y. 0000000023

19. Favretto S (2008) Applications of X-ray computed microtomography to materials science. VDM Publisher Dr, Müller

20. Favretto S, Scuor N, Zanini F, Lucchini E (2006) Use of X-ray computed tomography as a new non-destructive tool for the optimization of process parameters in hybrid friction sit welding/TIG technique. $8^{\circ}$ Convegno Nazionale AIMAT - Palermo (Italy)

21. Dinda SK, Kar J, Jana S, Roy GG, Srirangam P (2019) Effect of beam oscillation on porosity and intermetallics of electron beam 
welded DP600-steel to Al 5754-alloy. J Mater Process Technol 265:191-200. https://doi.org/10.1016/j.jmatprotec.2018.10.026

22. Teichmann F, Ziemer A, Leitner M, Hensel J, Dilger K (2020) Linear elastic FE-analysis of porous, laser welded, heat treatable, aluminium high pressure die castings based on X-ray computed tomography data. Materials 13(6):1420. https://doi.org/10.3390/ ma13061420

23. EN 13604 (2013) Copper and copper alloys - semiconductor devices, electronic and vacuum products made from high conductivity copper, $\mathrm{p} 8$

24. EN 13602 (2013) Copper and copper alloys - drawn, round copper wire for the manufacture of electrical conductors, $\mathrm{p} 9$

25. Stiedl J, Green S, Chassé T, Rebner K (2019) Characterization of Oxide layers on technical copper material using ultraviolet visible (UV-Vis) spectroscopy as a rapid on-line analysis tool. Appl Spectrosc 73(1):59-66. https://doi.org/10.1177/0003702818797959

26. Teichmann F, Pries H, Dilger K (2016) Multiple spot electron beam welding of aluminium die castings. In Proceedings of the 72nd World Foundry Congress (WFC 2016); Nagoya, Japan, 21-25 May 2016. World Foundry Organization, Publisher: Curran Associates Inc., Red Hook, NY

27. Marshall GF, Stutz GE (2012) Handbook of optical and laser scanning, 2nd edn. CRC Press, Publisher, $\mathrm{p} 9$

28. Stamopoulos AG, Tserpes KI, Prucha P, Vavrik D (2016) Evaluation of porosity effects on the mechanical properties of carbon fiber-reinforced plastic unidirectional laminates by X-ray computed tomography and mechanical testing. J Compos Mater 50(15):2087-2098. https://doi.org/10.1177/0021998315602049
29. Hemes S, Desbois G, Urai JL, Schröppel B, Schwarz J-O (2015) Multi-scale characterization of porosity in Boom Clay (HADESlevel, Mol, Belgium) using a combination of X-ray m-CT, 2D BIB-SEM and FIB-SEM tomography. Microporous Mesoporous Mater 208:1-20. https://doi.org/10.1016/j.micromeso.2015.01. 022

30. Glinz J, Senck S, Kastner J, Tondi G (2018) Determination of pore size distribution in Tannin- and Lignin-based foams using Xray microcomputed tomography, In Proceedings of the 8th Conference on Industrial Computed Tomography, 6-9 Feb, Wels, Austria, (iCT 2018). https://www.ndt.net/search/docs.php3?id=21945

31. Waddel H (1933) Sphericity and roundness of rock particles. J Geol 41(3):310-331. https://doi.org/10.1086/624040

32. Teichmann F, Müller S, Dilger K (2018) On the occurrence of weld bead porosity during laser vacuum welding of high pressure aluminium die castings. Procedia CIRP 74:438-441. https://doi. org/10.1016/j.procir.2018.08.163

33. Dinda S, Warnett J, Williams M, Roy GG, Srirangam P (2016) 3D imaging and quantification of porosity in electron beam welded dissimilar steel to $\mathrm{Fe}-\mathrm{Al}$ alloy joints by $\mathrm{X}$-ray tomography. Mater Des 96:224-231. https://doi.org/10.1016/j.matdes.2016.02.010

34. Harry MJ, Mann PS, De Hodgins OC, Hulbert RL, Lacke CJ (2010) Practitioner's guide to statistics and Lean Six Sigma for process improvement. John Wiley \& Sons, p 620

Publisher's note Springer Nature remains neutral with regard to jurisdictional claims in published maps and institutional affiliations. 